\title{
Identification of novel recessive gene $x a 44(t)$ conferring resistance to bacterial blight races in rice by QTL linkage analysis using an SNP chip
}

\author{
Suk-Man Kim ${ }^{1,2}$ (D)
}

Received: 25 July 2018 / Accepted: 8 September 2018 / Published online: 17 September 2018

(c) The Author(s) 2018

\begin{abstract}
Key message Using QTL analysis and fine mapping, the novel recessive gene $x a 44(t)$ conferring resistance to BB was identified and the expression level of the gene was confirmed through qRT-PCR analysis.

Abstract Bacterial blight (BB) disease caused by Xanthomonas oryzae pv. oryzae (Xoo) is a major factor causing rice yield loss in most rice-cultivating countries, especially in Asia. The deployment of cultivars with resistance to BB is the most effective method to control the disease. However, the evolution of new Xoo or pathotypes altered by single-gene-dependent mutations often results in breakdown of resistance. Thus, efforts to identify novel $R$-genes with sustainable BB resistance are urgently needed. In this study, we identified three quantitative trait loci (QTLs) on chromosomes 1, 4, and 11, from an $\mathrm{F}_{2}$ population of 493 individuals derived from a cross between IR73571-3B-11-3-K3 and Ilpum using a 7K SNP chip. Of these QTLs, one major QTL, $q B B \_11$, on chromosome 11 explained $61.58 \%$ of the total phenotypic variance in the population, with an LOD value of 113.59, based on SNPs 11964077 and 11985463 . The single major $R$-gene, with recessive gene action, was designated $x a 44(t)$ and was narrowed down to a 120-kb segment flanked within $28.00 \mathrm{Mbp}$ to $28.12 \mathrm{Mbp}$. Of nine ORFs present in the target region, two ORFs revealed significantly different expression levels of the candidate genes. These candidate genes (Os11g0690066 and Os11g0690466) are described as "serine/threonine protein kinase domain containing protein" and "hypothetical protein," respectively. The results will be useful to further understand BB resistance mechanisms and provide new sources of resistance, together with DNA markers for MAS breeding to improve BB resistance in rice.
\end{abstract}

\section{Introduction}

Bacterial blight (BB) is one of the most devastating diseases in rice (Oryza sativa L.) and is caused by Xanthomonas oryzae pv. oryzae (Xoo). The disease has been observed in rice-cultivation areas of Asia, the western coast of Africa,

Communicated by Takuji Sasaki.

Electronic supplementary material The online version of this article (https://doi.org/10.1007/s00122-018-3187-2) contains supplementary material, which is available to authorized users.

Suk-Man Kim

s.kim@irri.org

1 Strategic Innovation Platform, International Rice Research Institute, Los Baños, Philippines

2 IRRI-Korea Office, National Institute of Crop Science, Rural Development Administration, Jeollabuk-do 55365, Republic of Korea northern Australia, and Latin America, and yield loss due to BB in Asia is commonly reported as $20-30 \%$ in moderate conditions or up to $80 \%$ in certain environments (Reddy et al. 1979; Mew 1993; Nelson et al. 1994; Srinivasan and Gnanamanickam 2005). To prevent yield loss, the development of resistant varieties is suggested as the most effective method to control the disease without requiring collateral input from the farmer and having no environmental impact (McDowell and Woffenden 2003; Suh et al. 2009; Kim et al. 2015). However, the use of cultivars with a single major BB resistance gene ( $R$-gene) results in resistance breakdown by pathogen evolution and variation (Vera Cruz et al. 2000; Korinsak et al. 2009; Kobayashi et al. 2014; Dilla-Ermita et al. 2017). Thus, identification of new $R$ sources and the pyramiding of known $R$-genes are important methods to enhance sustainable and durable host resistance in the BBresistant breeding program. In particular $R$-gene pyramiding is a useful method to maximize the use of known $R$-genes, which appear to durable and broad-spectrum resistance to various races or isolates of a specific pathogen (Kim et al. 
2018). This $R$-gene combining approach with three or four genes were reported in various case of rice resistance breeding studies (Singh et al. 2001; Sundaram et al. 2008; Dokku et al. 2013; Suh et al. 2013; Pradhan et al. 2015).

Xoo is a rod-shaped gram-negative bacterium that invades rice tissue through wounds, stomata, or hydathodes (Mew 1987). The disease caused by Xoo is vascular, leading to a systemic infection that spreads from the leaf tips and margins, eventually releasing a milky ooze that dries into yellow droplets. In seedlings, plants are killed by BB within 2-3 weeks after infestation, exhibiting kresek, which occurs when the leaves dry out and wilt. In contrast, adult plants may survive, but rice yield and quality are diminished. The disease is prevalent in both tropical and temperate climates with warm $\left(25-30^{\circ} \mathrm{C}\right)$, humid, deep water, and rainy climates, which are beneficial for the spread of this disease, but not commonly found in North America (Sharma et al. 2017). In addition, severe winds causing wounds and excessive nitrogen fertilization also represent favorable conditions for the spread of the disease. Adhikari et al. (1995) assessed the diversity of Xoo using 308 BB strains from various Asian countries. The cluster analysis revealed 5 distinct genetic clusters from the collection, and seven pathotypes were determined by inoculation of five differential cultivars with the $R$-gene, demonstrating tight correspondence between clusters and national or regional origin (Adhikari et al. 1995). To date, approximately 43 genes conferring resistance to $\mathrm{BB}$ have been identified from various rice sources derived from Oryza sativa, wild relatives of rice and artificially induced mutants (Busungu et al. 2016; Dilla-Ermita et al. 2017). Approximately $62 \%$ of the total genes are dominant, including incomplete dominant genes, and 16 genes act in a recessive manner $(x a 5, x a 8$, $x a 9, x a 13, x a 15, x a 19, x a 20, x a 24, x a 25, x a 26 b, x a 28$, $x a 31, x a 32, x a 33, x a 34$, and $x a 42$ ) (Chen et al. 2011; Liang et al. 2017; Vikal and Bhatia 2017). Among the reported BB $R$-genes, only nine $R$-genes (Xa1, Xa3/Xa26, xa5, xal3, $X a 10, X a 21, X a 23, x a 25$, and $X a 27)$ have been characterized and functionally analyzed, revealing multiple mechanisms of $R$-gene-mediated Xoo resistance (Song et al. 1995; Iyer and Mccouch 2004; Sun et al. 2004; Gu et al. 2005; Chu et al. 2006; Tian et al. 2014). Xa4, Xa7, Xa22, Xa30, Xa31, Xa33, $x a 34, X a 35, X a 39, X a 40, x a 42$, and Xa42 loci were identified by fine mapping, and various ORFs within target regions were nominated as candidate genes explaining the trait. The $\mathrm{BB} R$-genes are evenly distributed throughout the 12 rice chromosomes. Of these genes, 8 are clustered on chromosome 11, whereas genes have not been reported on chromosomes 1, 9, and 10. While the use of BB-resistant cultivars is crucial to control the disease, resistance induced by a single major gene is easily reversed by pathogenic variation or evolution. Therefore, combining known $R$-genes has been recommended by many researchers as a promising strategy to reinforce durable resistance to BB, but accumulating multiple $R$-genes is difficult to achieve simply using phenotypic selection in conventional breeding programs. Given advancements in molecular technology, DNA markers associated with $R$-genes are being used for foreground selection or gene pyramiding to improve resistance in elite lines. Linkage or association mapping offers practical help to detect novel $R$-genes based on high-density DNA marker sets. Recently, the introduction of more efficient and cost effective marker systems assaying single nucleotide polymorphism (SNP) markers enables high-resolution genotyping for breeding applications in numerous crop species, including rice (Thomson et al. 2012). This technological progress facilitates association mapping, linkage mapping, and marker-assisted selection (MAS) (McCouch et al. 2010; Tung et al. 2010).

In this study, we report the use of QTL mapping resulting in the identification of a new recessive $R$-gene for $\mathrm{BB}$ resistance from IR73571-3B-11-3-K3 (P6). Evaluation of the degree of resistance of tested varieties was first performed using a range of BB isolates. Based on these results, mapping populations were developed to identify the resistant locus associated with BB resistance by QTL analysis using a 7-K SNP marker set. Key candidate genes known to be influential factors in plant-pathogen interactions were identified by PCR-based markers to identify new BB recessive $R$-genes.

\section{Materials and methods}

\section{Plant materials}

A total of $493 \mathrm{~F}_{2}$ individuals were produced from a cross between P6 and Ilpum and used for QTL analysis based on genotyping using the SNP chip and phenotyping based on bioassays. The parent P6 is one of eight parents from the japonica Multi-parent Advanced Generation Inter-Cross (JMAGIC) population (Bandillo et al. 2013) that exhibits resistance to Korean BB races and tolerance to salt stress. The other parent, Ilpum, is a high-quality japonica culti$\operatorname{var}$ (cv.) from Korea that lacks any BB R-genes. Some $F_{1}$ plants were also backcrossed with Ilpum to generate $\mathrm{BC}_{1} \mathrm{~F}_{1}$ plants. $\mathrm{F}_{1}$ and $\mathrm{BC}_{1} \mathrm{~F}_{1}$ plants were selected by PCR using SSR markers, and the $\mathrm{BC}_{1} \mathrm{~F}_{2}$ population was produced by self-pollination.

\section{DNA extraction and PCR}

DNA samples of plant materials were prepared at a final concentration of $50 \mathrm{ng} / \mu \mathrm{l}$ following the procedure described by Murray and Thompson (1980) with minor modifications and treated with RNAse I at $37{ }^{\circ} \mathrm{C}$ for $1 \mathrm{~h}$ for SNP genotyping. 
The concentrations of DNA samples were assessed using the Nanodrop ND 1000-spectro-photometer (Thermo Fisher Scientific, Inc., Wilmington, NC, USA) for nucleic acid quantification, and the quality of DNA samples was confirmed by visualization on $1.5 \%$ agarose gel. The PCR reaction was performed in an AllInOneCycler (BIONEER, Korea) in a total volume of $25 \mu \mathrm{l}$ with $10 \mathrm{ng}$ genomic DNA, $0.25-5 \mu \mathrm{M}$ SSR primer, $200 \mu \mathrm{M}$ dNTP mix, PCR buffer (containing $50 \mathrm{mM} \mathrm{KCl}, 10 \mathrm{mM}$ TRIS-Cl (pH 8.3), $3 \mathrm{mM} \mathrm{MgCl}$ ), and $0.5 \mathrm{U}$ of taq polymerase. The PCR profile was performed at an initial denaturation at $94{ }^{\circ} \mathrm{C}$ for $8 \mathrm{~min}$, followed by 32 cycles of denaturation at $94{ }^{\circ} \mathrm{C}$ for $30 \mathrm{~s}$, annealing at 55 or $60{ }^{\circ} \mathrm{C}$ for $30 \mathrm{~s}$, and extension at $72{ }^{\circ} \mathrm{C}$ for $30 \mathrm{~s}$, and a final extension at $72{ }^{\circ} \mathrm{C}$ for $8 \mathrm{~min}$.

\section{Phenotyping through bioassay}

To evaluate the resistance of the population to $\mathrm{BB}$ isolate HB1009 (K3a), the leaf-clipping method (Kauffman et al. 1973) was used at the maximum tillering stage of plants. The inoculation was performed in a paddy field $\left(\mathrm{F}_{2}\right.$ and $\left.\mathrm{F}_{1}\right)$ and under green house $\left(\mathrm{BC}_{1} \mathrm{~F}_{2}\right)$ conditions. According to the standard evaluation methods of the Rural Development Administration (RDA), Korea (RDA 2012), the average lesion length due to leaf damage of three leaves was measured 14 days after the inoculation. Plants with a lesion length of $<3 \mathrm{~cm}$ were categorized as resistance $(\mathrm{R})$, whereas those with a lesion length of $>5 \mathrm{~cm}$ were categorized as susceptibility $(\mathrm{S})$. For cases with lesion lengths within $3-5 \mathrm{~cm}$, the plants were moderate resistance (MR). Both of $\mathrm{R}$ and $\mathrm{MR}$ were considered as resistant type in this study.

\section{Genotyping and linkage mapping}

The Infinium 7K BeadChip composed of 384 SNP sets customized for the indica-japonica SNP chip (ID: GS0011862OPA) was used for genotyping. To construct a linkage map of the tested population, SNPs exhibiting polymorphisms between P6 and Ilpum were selected by the parental survey. Some SNPs were removed because segregation distortion appeared within SNPs, or anchored positions overlapped with each other. Compared with the expected segregation ratio $(1: 2: 1)$, segregation distortion was identified using the MAP functionality of QTL IciMapping version 4.0 software (Meng et al. 2015). Based on quality standards for SNPs, only appropriate SNPs were selected and used to construct a genetic linkage map of the mapping population.

\section{QTL mapping}

QTL analysis was conducted using conventional interval mapping for additive QTL (IM-ADD) and inclusive composite interval mapping for additive QTL (ICIM-ADD).
Significance thresholds were determined using 1000 permutations defined at $P \leq 0.05$. "By LOD" and "By Input" functional options in the IciMapping program referred to the grouping and ordering of anchored SNPs. Mapping distance was calculated by recombination frequency using the Kosambi mapping function. For QTL mapping, genotypic data from SNPs and phenotypic data from measurement of lesion length of damaged lines were combined to detect QTLs related to resistance to $\mathrm{BB}$.

\section{Devolvement of markers to narrow down the target region}

Additional DNA markers were developed within the target region to perform fine mapping. A total of 125 PCR-based DNA markers (Supplementary Table 1) were tested to identify polymorphisms in parents of the mapping population. Nine DNA markers within the region were then selected from the Rice Annotation Project Database (RAP-DB, http:// rapdb.dna.affrc.go.jp/). Markers for detecting InDel polymorphisms were developed within the target region using the DNA polymorphism database (Shen et al. 2004). To design primers for InDel markers, we followed the method of Kim et al. 2015. CAP markers were developed by direct sequencing of the PCR amplicon to identify specific sites for restriction enzyme using NEBcutter 2.0 (Vincze et al. 2003).

\section{RNA isolation and quantitative real-time PCR}

Total RNA was extracted from rice seedlings using the TRIzol reagent (Invitrogen, Carlsbad, CA, USA) according to the manufacturer's protocols. The amfiRivert cDNA Synthesis Platinum Master Mix (GenDEPOT, Barker, TX, USA) was used for cDNA synthesis according to protocols provided by the manufacturer. Diluted cDAN was analyzed by using Stratagene MX3005P qPCR System (Agilent) and amfiSure qGreen Q-PCR Master Mix (GenDEPOT, Barker, TX, USA) for gene expression. To evaluate transcript levels, the rice $e E F 1-\alpha$ gene was used as an internal control for qRT-PCR data normalization (Yokotani et al. 2013). Each set of experiments was repeated three times, and the ddCT relative quantification method was used to evaluate the quantitative variation. Primers used to amplify the selected genes are listed in Supplementary Table 4.

\section{Results}

\section{Screening leaf reactions to different BB isolates}

$\mathrm{BB} R$-donors $\mathrm{P} 6$ and $\mathrm{P} 8$ were resistant to $\mathrm{BB}$ race $\mathrm{K} 3 \mathrm{a}$, and $R$-gene loci detected from both donors were delimited by the same flanking markers noted in our previous GWAS analysis 
(not published). We then sought to determine whether these donors contained different $R$-genes. To determine the race specificity of $R$-gene(s) from each strain against the BB isolates, the leaf-clipping inoculation method was performed with a total of 24 BB isolates from Korea (Table 1). Of 24 isolates the $R$-donor P6 exhibited resistance ( $\leqq 5 \mathrm{~cm}$ ) to 20 isolates but was susceptible ( $>5 \mathrm{~cm}$ ) to four isolates, HB3055, 3079, 4024, and HB4044. P8 was resistance to all tested isolates. No differences in $R$-reactions were noted between P8 and 11325, which harbors $X a 40$ closely linked to the detected position. Based on

Table 1 Leaf reactions of four lines to 24 BB isolates 14 days after inoculation. The three lines P6, P8, and 11325 are resistant to BB isolate K3a (HB1009), and Ilpum is used as a control for susceptibility. Average lesion length was obtained after measuring three leaves

\begin{tabular}{|c|c|c|c|c|}
\hline \multirow[t]{2}{*}{ Isolate } & \multicolumn{4}{|c|}{$\begin{array}{l}\text { Lesion length of tested line and cultivars to } 24 \mathrm{BB} \\
\text { isolates }(\mathrm{cm})\end{array}$} \\
\hline & P6 & P8 & 11325 & Ilpum \\
\hline HB1009 & $3.0 \pm 2.3$ & $1.5 \pm 0.8$ & $1.8 \pm 0.5$ & $12.0 \pm 2.0$ \\
\hline HB1013 & $2.5 \pm 0.0$ & $2.0 \pm 0.0$ & $1.0 \pm 2.2$ & $10.1 \pm 3.1$ \\
\hline HB1014 & $0.5 \pm 1.7$ & $0.5 \pm 0.0$ & $4.0 \pm 2.2$ & $7.7 \pm 3.1$ \\
\hline HB1015 & $4.0 \pm 0.0$ & $2.0 \pm 0.7$ & $1.3 \pm 2.0$ & $8.0 \pm 0.8$ \\
\hline HB2010 & $0.5 \pm 0.6$ & $0.5 \pm 1.2$ & $1.0 \pm 0.1$ & $10.0 \pm 4.5$ \\
\hline HB2024 & $5.5 \pm 1.0$ & $2.5 \pm 2.0$ & $3.7 \pm 1.5$ & $12.5 \pm 5.2$ \\
\hline HB2038 & $4.3 \pm 0.0$ & $3.5 \pm 0.2$ & $2.0 \pm 2.0$ & $12.3 \pm 3.2$ \\
\hline HB3011 & $0.5 \pm 2.4$ & $0.7 \pm 0.1$ & $5.0 \pm 1.8$ & $10.3 \pm 3.0$ \\
\hline HB3034 & $4.8 \pm 1.2$ & $4.5 \pm 1.8$ & $6.5 \pm 0.5$ & $12.3 \pm 2.0$ \\
\hline HB3055 & $9.0 \pm 2.4$ & $3.5 \pm 1.7$ & $4.5 \pm 0.7$ & $10.3 \pm 3.1$ \\
\hline HB3079 & $10.0 \pm 1.2$ & $2.5 \pm 0.7$ & $3.5 \pm 0.7$ & $11.3 \pm 5.5$ \\
\hline HB4024 & $20.0 \pm 4.2$ & $3.3 \pm 1.5$ & $1.0 \pm 0.0$ & a \\
\hline HB4027 & $0.5 \pm 0.3$ & $0.5 \pm 0.0$ & $3.5 \pm 0.0$ & $6.0 \pm 2.6$ \\
\hline HB4030 & $6.3 \pm 3.5$ & $3.5 \pm 0.7$ & $6.0 \pm 2.1$ & $12.5 \pm 3.5$ \\
\hline HB4032 & $5.5 \pm 2.8$ & $3.5 \pm 0.7$ & $4.0 \pm 2.8$ & $10.3 \pm 3.2$ \\
\hline HB4040 & $6.0 \pm 0.0$ & $4.0 \pm 1.4$ & $2.5 \pm 1.4$ & $10.0 \pm 1.0$ \\
\hline HB4044 & $7.0 \pm 2.8$ & $3.7 \pm 0.5$ & $2.3 \pm 2.1$ & $11.0 \pm 2.6$ \\
\hline HB4052 & $5.0 \pm 3.5$ & $4.8 \pm 0.3$ & $2.0 \pm 0.5$ & $7.5 \pm 0.7$ \\
\hline HB4074 & $7.5 \pm 2.4$ & $4.0 \pm 0.0$ & $2.0 \pm 1.7$ & $12.3 \pm 2.5$ \\
\hline HB4079 & $5.0 \pm 0.7$ & $5.0 \pm 1.4$ & $4.0 \pm 0.0$ & $8.5 \pm 0.7$ \\
\hline HB4084 & $4.5 \pm 4.9$ & $4.0 \pm 0.0$ & $2.5 \pm 1.7$ & $11.3 \pm 5.7$ \\
\hline HB4087 & $6.5 \pm 1.4$ & $4.8 \pm 2.0$ & $2.3 \pm 2.1$ & $6.0 \pm 2.8$ \\
\hline HB5004 & $4.0 \pm 2.1$ & $4.0 \pm 2.4$ & $3.3 \pm 0.5$ & $8.5 \pm 3.0$ \\
\hline HB6142 & $5.5 \pm 2.1$ & $3.5 \pm 0.7$ & $3.5 \pm 1.4$ & - \\
\hline
\end{tabular}

Bold indicates a different reaction among P6, P8, and 11325

${ }^{\mathrm{a}}$ Is missing data the leaf-reaction results, P6 exhibited resistance to greater than 20 isolates, but obvious differences in resistance to HB3055, 3079, 4024, and HB4044 were noted in P8 and 11325. Leafreaction results confirmed that Ilpum was susceptible to all tested isolates (Table 1).

\section{Development of the mapping population and R-gene inheritance}

To determine the $R$-gene associated with the resistance of $\mathrm{P} 6$, a total of $493 \mathrm{~F}_{2}$ individuals were produced from a cross between $\mathrm{P} 6$ as the $R$-donor and the japonica cultivar (cv.) Ilpum that does not harbor any $\mathrm{BB} R$-genes. To narrow down the target region associated with the $R$-gene, $42 \mathrm{BC}_{1} \mathrm{~F}_{1}$ individuals were developed by a backcross. Ten $\mathrm{BC}_{1} \mathrm{~F}_{1}$ plants selected from the genotype survey using SSR markers were self-pollinated to generate the $\mathrm{BC}_{1} \mathrm{~F}_{2}$ population. A total of $520 \mathrm{BC}_{1} \mathrm{~F}_{2}$ individuals were used for fine mapping of the target region associated with the $R$-gene. Phenotyping by measurement of lesion length was performed using each of the $\mathrm{F}_{2}$ individuals. The population had a lesion length ranging from 0.1 to $30 \mathrm{~cm} 14$ days after inoculation (DAI). Based on the standard evaluation method, the plants segregated phenotypically as 127 resistant and 366 susceptible lines, fitting the expected phenotypic ratio of 1:3, with $X^{2}=0.15$ and $P=0.69(P>0.05)$ (Table 2). For the $\mathrm{BC}_{1} \mathrm{~F}_{2}$ population, the segregation ratio also followed the expected segregation ratio for a recessive gene of $1: 3$ (R:S), with $X^{2}=1.22$ and $P=0.26(P>0.05)$ (Table 2$)$. These findings confirmed a single recessive resistance gene conferring Xoo resistance in P6.

\section{Linkage mapping}

A total of 7098 SNPs were first used to construct a linkage map for the $F_{2}$ mapping population. From the $7 \mathrm{~K}$ SNP chip analysis, a total of 6658 SNPs were called from the analysis and used for the linkage mapping. Using the parental survey, SNPs exhibiting polymorphic patterns between parents were selected, and heterologous SNPs and deletion and insertion types were removed. From this process, 2983 SNPs were used to construct the linkage map, for an average polymorphism rate of $42.0 \%$. On average, 248 SNPs were anchored on each rice chromosome by QTL IciMapping (Table 3, Fig. 1a). Using linkage map information supported by the software, we detected 1029 redundant SNPs that overlapped the same position on each chromosome with a $0-\mathrm{cM}$ interval. The linkage
Table 2 Genetic analysis of BB-resistant response of $\mathrm{F}_{2}$ and $\mathrm{BC}_{1} \mathrm{~F}_{2}$ from the cross between $\mathrm{P} 6$ and Ilpum against the BB race $\mathrm{K} 3 \mathrm{a}$

\begin{tabular}{lllllll}
\hline Cross (generation) & Number of $R$ & Number of $S$ & Total number & $\begin{array}{l}\text { Segregation } \\
\text { ratio }\end{array}$ & $X^{2}$ & $P$ \\
\hline P6/Ilpum $\left(\mathrm{F}_{2}\right)$ & 127 & 366 & 493 & $1: 3$ & 0.15 & 0.69 \\
P6/Ilpum $\left(\mathrm{BC}_{1} \mathrm{~F}_{2}\right)$ & 115 & 388 & 503 & $1: 3$ & 1.22 & 0.26 \\
\hline
\end{tabular}


Table 3 Distribution of SNPs on 12 rice chromosomes exhibiting polymorphisms in the parental survey

\begin{tabular}{lcclcc}
\hline Chromosome & Tested markers & $\begin{array}{l}\text { Polymorphic } \\
\text { markers }\end{array}$ & $\begin{array}{l}\text { Polymorphic } \\
\text { rate (\%) }\end{array}$ & Selected marker & $\begin{array}{l}\text { Selected } \\
\text { rate }(\%)\end{array}$ \\
\hline Chr 1 & 850 & 373 & 43.9 & 176 & 20.7 \\
Chr 2 & 660 & 273 & 41.4 & 104 & 15.8 \\
Chr 3 & 683 & 365 & 53.4 & 234 & 34.3 \\
Chr 4 & 646 & 255 & 39.5 & 178 & 27.6 \\
Chr 5 & 509 & 219 & 43.0 & 180 & 35.4 \\
Chr 6 & 551 & 323 & 58.6 & 178 & 32.3 \\
Chr 7 & 524 & 89 & 17.0 & 72 & 13.7 \\
Chr 8 & 545 & 219 & 40.2 & 148 & 27.2 \\
Chr 9 & 455 & 193 & 42.4 & 157 & 34.5 \\
Chr 10 & 472 & 218 & 46.2 & 158 & 33.5 \\
Chr 11 & 631 & 284 & 45.0 & 184 & 29.2 \\
Chr 12 & 572 & 263 & 46.0 & 185 & 32.3 \\
Total & 7098 & 2983 & 42.0 & 1954 & 27.5 \\
\hline
\end{tabular}

Fig. 1 Histogram of lesion length of plants tested using the $\mathrm{BB}$ race $\mathrm{K} 3 \mathrm{a}$. Plants were classified as resistant when it had lesion length of less than $5 \mathrm{~cm}$ at 14 DAI, and this classification includes both resistant and moderately resistant plants. $R$-donor P6 was resistant to $\mathrm{K} 3 \mathrm{a}$, with lesion lengths of less than $2.5 \mathrm{~cm}$, and Ilpum was susceptible, with lesion lengths greater than $10 \mathrm{~cm} . \mathrm{F}_{1}$ plants exhibited lesion lengths in the range of $5-7.5 \mathrm{~cm}$

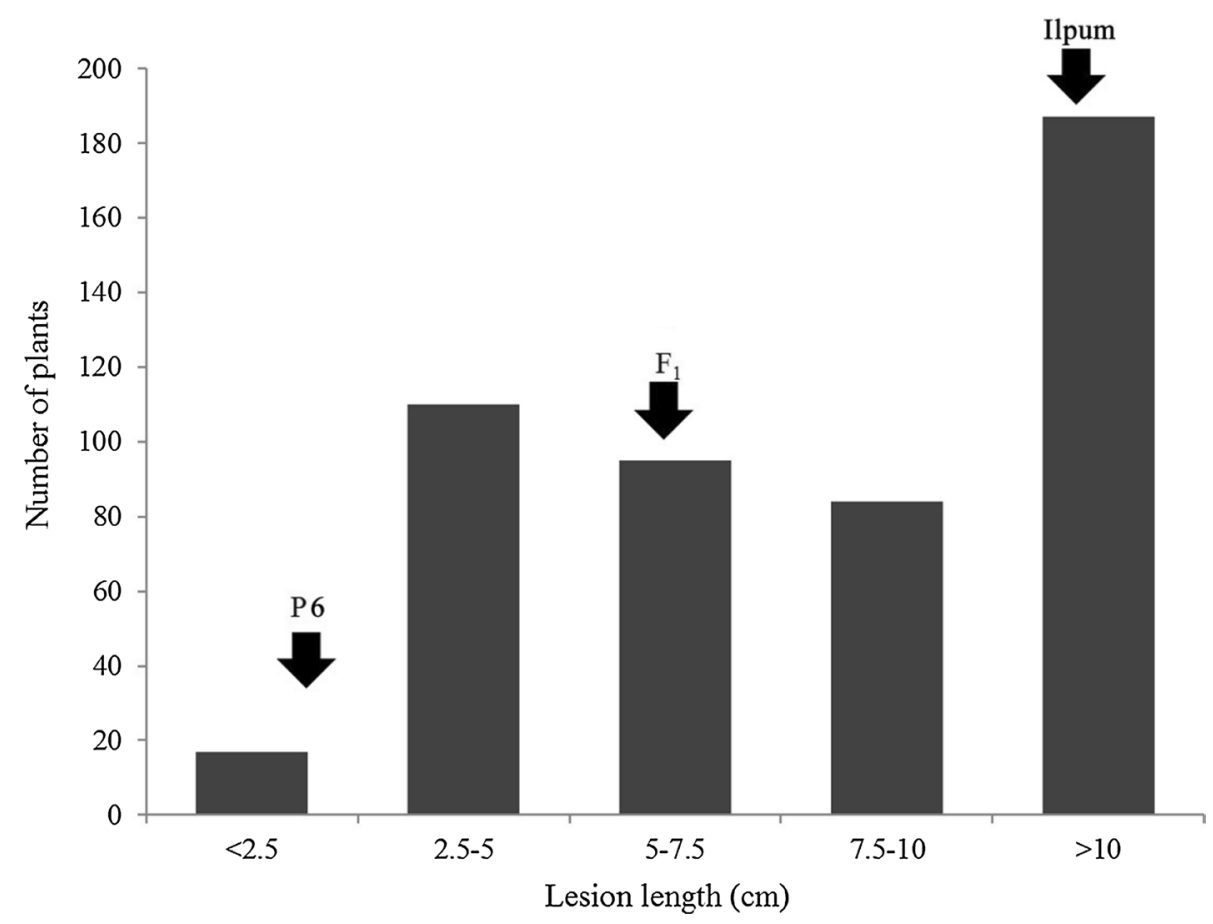

map was ultimately constructed with a total of 1954 SNPs, with approximately 163 SNPs anchored in each chromosome on average (Table 3$)$.

\section{QTL analysis}

The distribution of $\mathrm{BB}$ damage of the $\mathrm{F}_{2}$ mapping population revealed a wide range of lesion lengths (Fig. 2). Genotypes of the population were analyzed using 1954 SNPs out of 7K SNP chips and were calculated along with the phenotypic data to detect QTLs associated with BB $R$-genes conferring resistance to Xoo. Three QTLs were detected on chromosomes 1, 4, and 11 (Table 4). Of these QTLs, QTLs on chromosomes 4 and 11 revealed a negative influence on the alleles derived from the BB-resistant parent P6, whereas the additive effects of $q B B \_l$ were positive. One QTL, $q B B \_1$, with an LOD score of 9.23 was detected within SNP-1.40447508 and SNP-1.40570714 on chromosome 1, explaining $2.97 \%$ of phenotypic variation $\left(R^{2}\right)$ in ICIM analysis. In addition, $q B B \_4$, with an LOD of 7.63, was detected within flanking markers (4412887 and 4439600) on chromosome 4 with an $R^{2}$ of 2.67. As a major QTL, $q B B \_11$ detected on the long arm of chromosome 11 and was directly related to $\mathrm{P} 6$ resistance to the $\mathrm{BB}$ race $\mathrm{K} 3 \mathrm{a}$. The $R^{2}$ explained 


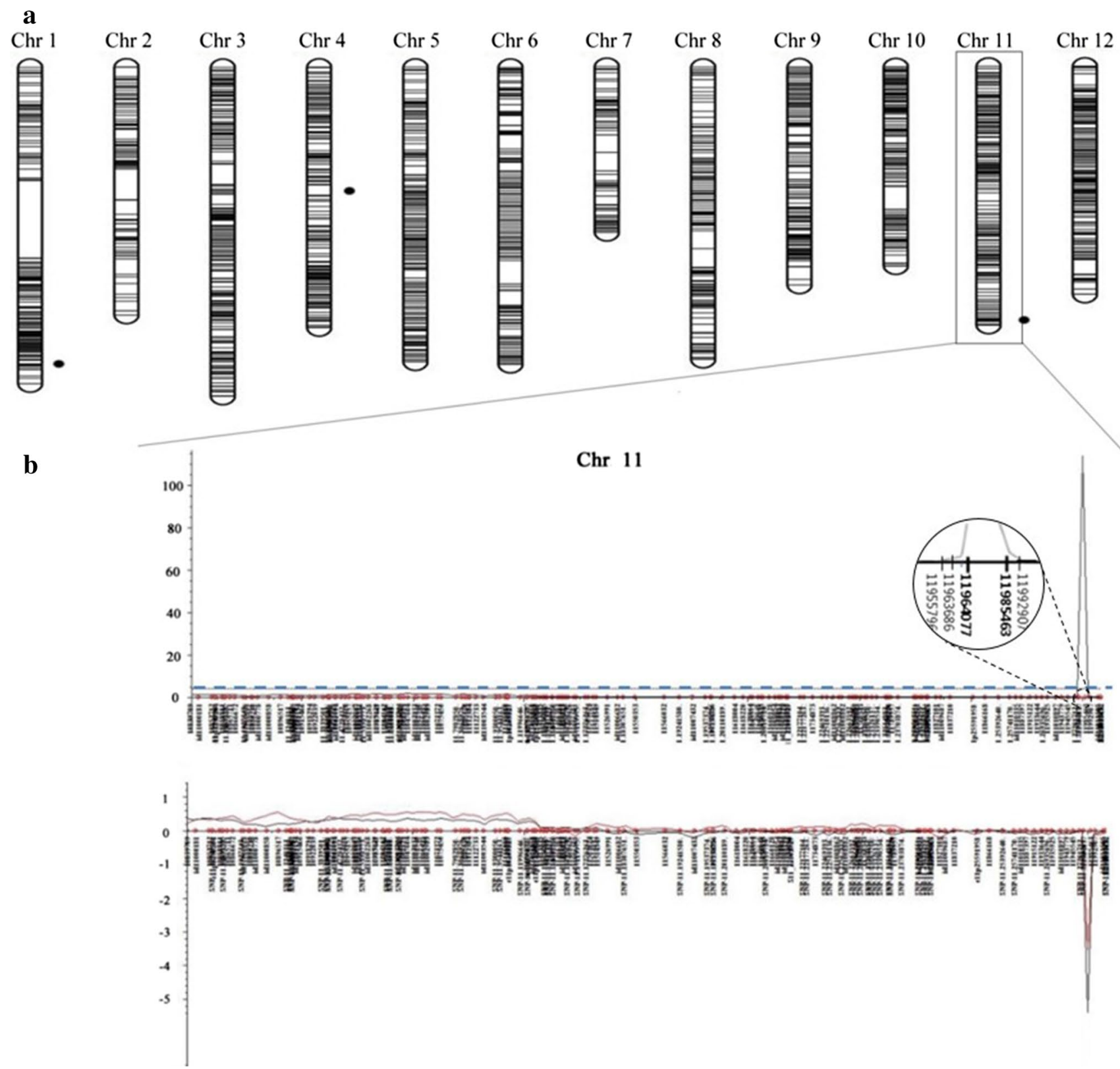

Fig. 2 Linkage map and QTL analysis using $\mathrm{F}_{2}$ mapping population. a Genetic linkage map of the 12 chromosomes based on 1954 SNP markers segregating in the P6/Ilpum $493 \mathrm{~F}_{2}$ plants. Black dots beside chromosomes 1, 4, and 11 represent the positions of detected QTLs. b The LOD profile and additive effect of major QTL analyzed by inclusive composite interval mapping on chromosome 11. The SNP location was positioned in the whole genome. The positive additive effect was derived from the susceptible parent Ilpum, whereas the negative value was related to the resistant parent. The dotted line is LOD threshold calculated by 1000 permutations

Table 4 Putative QTLs associated with the BB $R$-gene from P6 detected by composite and interval mapping

\begin{tabular}{llrrllrrrr}
\hline Analysis & QTLs & Chr & Position $(\mathrm{cM})$ & L marker & R maker & LOD & $R^{2}(\%)$ & Add & Dom \\
\hline ICIM & $\boldsymbol{q B B \_ 1 1}$ & 11 & 160 & 11964077 & 11985463 & 113.59 & 61.58 & -5.39 & -3.53 \\
& $q B B \_4$ & 4 & 81 & 4412887 & 4439600 & 7.63 & 2.67 & -1.09 & -0.27 \\
& $q B B \_1$ & 1 & 186 & SNP-1.40447508 & SNP-1.40570714 & 9.23 & 2.97 & 1.21 & 0.36 \\
\hline
\end{tabular}

ICIM inclusive composite interval mapping, $R^{2}$ percent phenotypic variation explained by the QTL, Add additive effect, Dom dominant effect 
$61.58 \%$ in ICIM analysis, with an LOD of 113.59 , and this QTL harbored SNPs 11964077 and 11985463 . The detected QTL was also confirmed to exhibit a mixture of an additive effect $(-5.39)$ and dominant effect $(-3.53)$.

\section{Identification of target regions}

Additional DNA markers were developed to dissect the interval containing QTL $q B B \_11$, which is defined by flanking markers 11964077 and 11985463 (Fig. 3a). Of 125 markers newly designed for fine mapping, nine were selected for fine mapping based on the parental survey. Six Nipponbare BAC clones (Load ID: OSJNBa0047M04, OSJNBa001L01, OSJNBa0036K13, OSJNBa0004O15, OSJN$\mathrm{Ba} 0059 \mathrm{H} 21$, and OSJNBa005C17) were located within in the target region within approximately $\sim 490 \mathrm{Kbp}$, indicating the physical position (Fig. 3a). To delimit the physical location of the $R$-gene, $\mathrm{BC}_{1} \mathrm{~F}_{2}$ individuals were used, and sixteen recombinants were finally selected through the analysis of discordance by genotyping and phenotyping. The selected DNA markers were arranged between flanking markers
\#STS1150/HinfI, and \#21.RM27340, which are both close to the terminal position (Fig. 3b). According to the number of recombinant events, the target region was further narrowed down toward the left flanking marker \#STS1150/HinfI. Thus, the $R$-gene is located in the flanking region of the approximately $120-\mathrm{Kbp}$ segment delimited by two DNA markers \#46. Os11g0689400 and \#5. RM27318 (Fig. 3b). In the case of SSR marker RM27316, no recombinant event was found within the target region (Fig. 3b, Supplementary Table 3). Nine ORFs located in the target region were identified as candidate genes conferring resistance to BB (Supplementary Table 2). Two ORFs, Os11g0690066 and Os11g0690332, encoded proteins related to kinase domain, and the remaining seven ORFs encoded hypothetical protein and non-protein coding transcript, separately.

\section{Expression analysis of candidate genes in the target region}

An additional primer set was designed to analyze expression levels of candidate genes based on genetic sequence

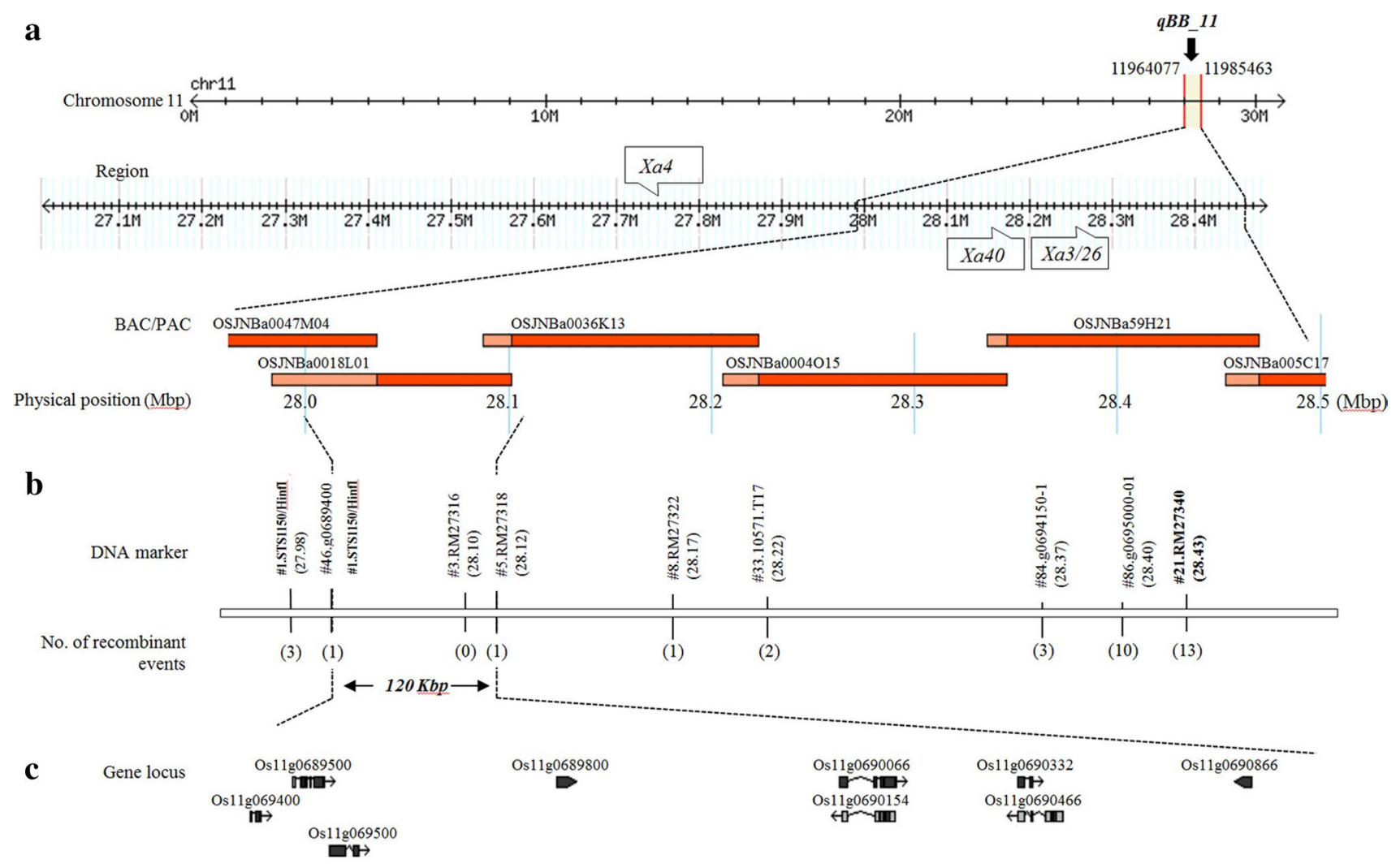

Fig. 3 Dissection of $q B B_{-} 11$ regions. a The physical position of anchored marker on the chromosome 11 present based on the Nipponbare genome. Three BB R-genes were clustered near the target region in which loci $\mathrm{Xa} 40$ and Xa3/26 were included. b The target region flanked by the STS marker \#1.STS1150/HinfI and SSR marker \#21.RM27340 from the QTL analysis. The number in brackets indi- cates the number of recombinant events detected among P6 $\times$ Ilpum $\mathrm{BC}_{1} \mathrm{~F}_{2}$ individuals. $\mathbf{c}$ The loci of ORFs listed in the target region that resulted from the fine mapping based on RAP-DB (IRGSP-1.0). Nine candidates for the BB $R$-gene were included in approximately 120 $\mathrm{Kbp}$ of the target region 
using RAP-DB (Supplementary Table 4). Of nine candidate genes two genes, Os11g0690066 and Os11g0690466, exhibited up-regulation of expression levels in P6 were significantly higher than that in Ilpum (Fig. 4). The expression level of Os11g0690066 in P6 at $4 \mathrm{~h}$ after inoculation was observed as significantly up-regulated expression at a level of 11 times (3.48 of $\log 2$ fold changes) of the concentration at $0 \mathrm{~h}$ (Fig. 4a). In particular the expression level of Os110690466 was considerable increase at $2 \mathrm{~h}$ to soar at $4 \mathrm{~h}$ and maintained as it declined until $24 \mathrm{~h}$ (Fig. 4b). While remaining ORFs revealed no significant difference between both lines (data not shown).

\section{Discussion}

$\mathrm{BB}$ is one of the main rice production constraints in many rice-growing areas. Currently, the development and deployment of resistant cultivars carrying major $R$-gene(s) represent the most effective method to control this rice disease. However, the high degree of pathogenic variation in Xoo often causes the breakdown of resistance to new virulent BB strains. Therefore, diversifying the germplasm is urgently needed through the identification of resistance genes from wild species and pyramiding two or more effective resistance genes in developing rice cultivars with sustainable BB resistance to Xoo.

In this study, we developed an $\mathrm{F}_{2}$ population from a cross between the BB $R$-donor P6 and the susceptible japonica cv. Ilpum to detect the position of the $R$-gene conferring resistance to the $\mathrm{BB}$ race $\mathrm{K} 3 \mathrm{a}$ by $\mathrm{QTL}$ analysis. To narrow down the detected target region, fine mapping was performed for the $\mathrm{BC}_{1} \mathrm{~F}_{2}$ population using additional DNA markers. Based on the QTL analysis, one major QTL $q B B \_11$ was identified at the end of chromosome 11, exhibiting a resistant response to the tested BB isolate. As a major single recessive $R$-gene, this gene has a high LOD value of 113.59, explaining $61.58 \%$ of the phenotypic variation. In previous studies, approximately 43 BB $R$-genes have been reported in rice cultivars, their wild relatives and mutant populations (Busungu et al. 2016). Although recessive resistance is relatively uncommon in plant bacterial systems, the ratio of recessive genes is approximately $38 \%$ in nature among all BB $R$-genes, and $R$-genes are distributed on various chromosomes, such as chromosome 1 (xa34), chromosome 2 (xa24), chromosome 3 (xa42), chromosome 4 (xa31), chromosome 5 (xa5), chromosome 6 (xa33), chromosome 7 (xa8), chromosome 8 (xa13), chromosome 11 (xa9), and chromosome 12 (xa25) (Korinsak et al. 2009; Liu et al. 2011; Liang et al. 2017). In addition, three recessive $R$-genes $x a 15$, xa19, and $x a 20$ were induced in mutant lines (Vikal and Bhatia 2017), and two $R$-genes $x a 26$ and $x a 28$ were identified by genetic analysis (Lee et al. 2003). To date, only nine $R$-genes have been isolated and cloned, including Xa1, Xa3/Xa26, $x a 5$, $X a 10, x a 13, X a 21, X a 23, x a 25$, and Xa27, and five types of proteins are encoded by these genes (Gu et al. 2004; Iyer and Mccouch 2004; Sun et al. 2004; Liu et al. 2011; Tian et al. 2014; Wang et al. 2015). Among these genes, three recessive $R$-genes have been characterized. The recessive gene $x a 5$ encodes the gamma subunit of transcription factor

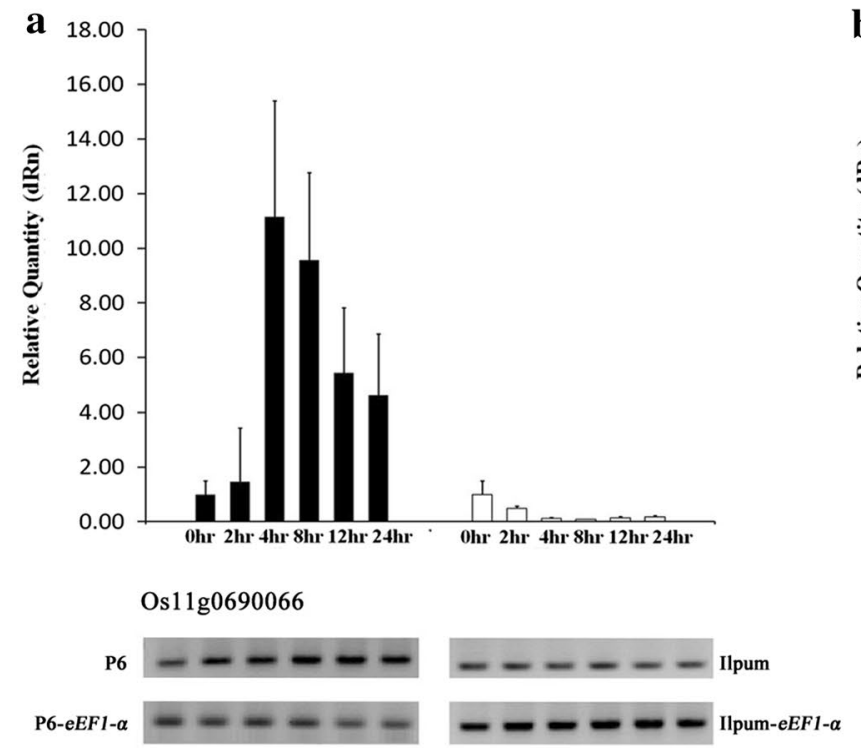

Fig. 4 qRT-PCR analysis for gene expression pattern of P6 and Ilpum after BB inoculation. a mRNA expression levels of Os11g0690066 at six time-points $(0,2,4,8,12$, and 24) after inoculations for both P6

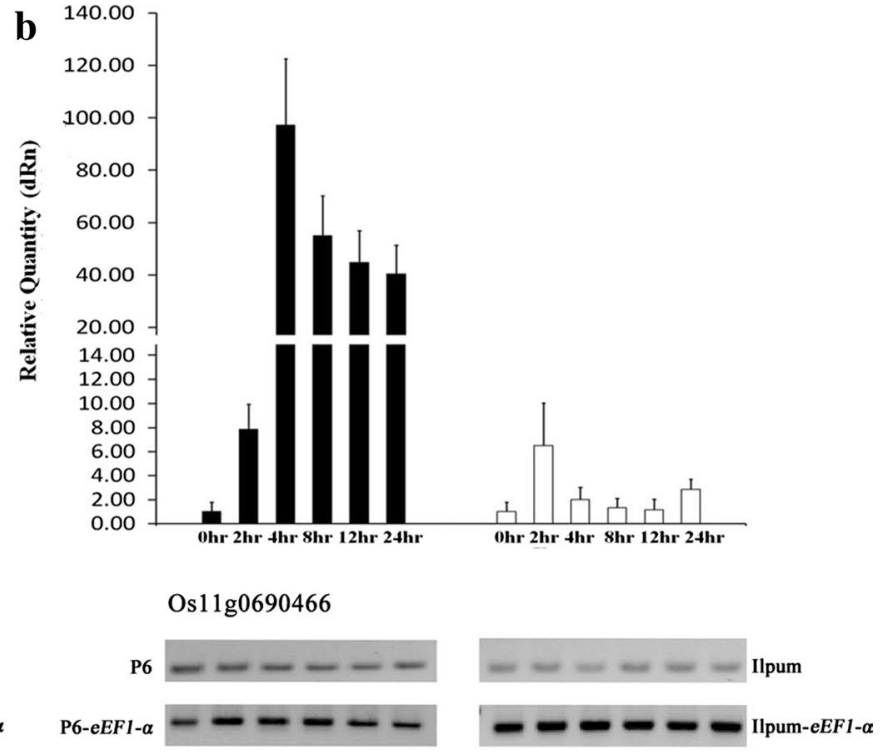

and Ilpum rice varieties, respectively. $\mathbf{b}$ mRNA expression levels of Os11g0690466 at six time-points $(0,2,4,8,12$, and 24) after inoculations for both P6 and Ilpum rice varieties, respectively 
IIA, and recessive gene $x a 13$ encodes a novel plasma membrane protein that originated from the aus genotype (Iyer and Mccouch 2004; Chu et al. 2006; Iyer-Pascuzzi and McCouch 2007). The recessive gene $x a 25$ derived from sativa spp. indica encodes a nodulin MtN3 family protein essential for reproductive development and rice-Xoo interaction (Liu et al. 2011). Six recessive $R$-genes ( $x a 8, x a 24, x a 31, x a 33$, $x a 34$, and $x a 42$ ) were identified by fine genetic mapping.

In this study, we identified a new recessive BB $R$-gene designated $x a 44(t)$ and detected the locus on chromosome 11 by fine mapping. In addition, the locus of the $R$-gene detected in this study contains a closely linked cluster of at least three $R$-genes that were identified in a nearby region as Xa3/Xa26, Xa4 and Xa40. In particular, Xa3 and Xa40 were included within the target region (Fig. $3 \mathrm{a}$ ). However, the $R$-gene $x a 44(t)$ recessively segregated to the BB isolate comparing adjoining dominant $R$-genes $\mathrm{Xa} 3$ and $\mathrm{Xa} 40$, and $\mathrm{X} a 3$ was particularly susceptible to the $\mathrm{BB}$ race $\mathrm{K} 3 \mathrm{a}$ (Kim et al. 2015). Thus, bioassays were performed to confirm BB isolate specificity with another $R$-gene, Xa40, using 24 isolates in Korea (Table 1). The result showed that $x a 44(t)$ and the other $R$-genes exhibited different $R$-reactions to four of the tested isolates. As a major QTL, $q B B \_11$ was eventually identified by linkage analysis, and six Nipponbare BAC clones (OSJNBa0047M04, OSJNBa0018L01, OSJNBa0036K13, OSJNBa0004O15, OSJNBa0059H21, and OSJNBa005C17) were included in the detected target region of approximately 490-Kbp. To further narrow down the target region flanked by SNPs, additional PCRbased markers were developed within the target region and selected by the parent survey. Through fine mapping using $520 \mathrm{BC}_{1} \mathrm{~F}_{2}$ individuals, the $R$-gene $x a 44(t)$ was delimited to an approximately $120-\mathrm{Kbp}$ segment flanked by DNA markers \# 46.g0689400 and RM 27318, and nine putative ORFs involved with the $R$-gene were identified based on the current gene annotation (Fig. 3b, c; Supplementary Table 2). To confirm the candidate gene $x a 44(t)$, qRT-PCR was performed using new primer set designed based on the exons of candidates (Supplementary Table 4). Expression levels of two genes Os11g0690066 (Os11g0690154) and Os11g069466 were significantly higher than that of Ilpum (Fig. 4). Os11g0690066 encoded a "serine/threonine protein kinase domain containing protein," which is known as an influential factor in plant-pathogen interactions (Cao et al. 2011; Lee and Kim 2015). The protein serine/threonine kinase encoded by the candidate has been reported in several crops on disease resistance. BB $R$-gene $X a 21$ in rice (Liu et al. 2002), barley stem rust $R$-gene Rpg 5 (Brueggeman et al. 2008), tomato bacterial speck disease $R$-gene Pto (Martin et al. 1993), wheat stripe rust $R$-gene $\operatorname{Yr} 36$ (Fu et al. 2009) are related to the protein. Further Os11g0690466 encoding a hypothetical protein was shown to have a much higher expression level in P6 than that of Os11g0690066.
However, the function of Os11g0690466 is difficult to define due to lack of identity to protein sequences with annotated biochemical function. In addition, we are also considering possibility that two genes can be actually a single gene due to false annotation like case of Bph18 (Ji et al. 2016). Given the results of the fine mapping and qRT-PCR, it is highly likely that the two ORFs are related to BB resistance of $x a 44(t)$.

In this study, we identified a new BB recessive $R$-gene designated $x a 44(t)$ by QTL analysis and fine mapping using various molecular markers sets. PCR-based DNA markers tightly linked to the $R$-gene were developed for MAS, and key ORFs were suggested as likely candidates for $x a 44(t)$. These will be especially useful for BB breeding programs as the $R$-gene exhibits resistance to the four main $\mathrm{BB}$ races, $\mathrm{K} 1, \mathrm{~K} 2, \mathrm{~K} 3$, and $\mathrm{K} 3 \mathrm{a}$, which represent approximately $95 \%$ of races in Korea, conferring broad-spectrum resistance to Xоo in Korea. The results provide further useful information to understand BB resistance mechanisms and provide DNA markers for MAS breeding to improve BB resistance in rice. Further studies to characterize $x a 44(t)$ gene structure, protein sequence, and biochemical function will be required.

Author Contribution statement SMK carried out all researches regarding the study anddrafted the manuscript.

Acknowledgements This research was supported in part by a grant to the Agenda Program (Code No. PJ013807-04); the Temperate Rice Research Consortium (TRRC) of the Rural Development Administration, Republic of Korea; and the Global Rice Science Partnership (GRiSP) program of IRRI. I thank Dr. R. Reinke for carefully editing and revising the manuscript.

\section{Compliance with ethical standards}

Conflict of interest The authors declare that they have no conflict of interest.

Ethical standards The experiments comply with the current laws of the country in which they were performed.

Open Access This article is distributed under the terms of the Creative Commons Attribution 4.0 International License (http://creativeco mmons.org/licenses/by/4.0/), which permits unrestricted use, distribution, and reproduction in any medium, provided you give appropriate credit to the original author(s) and the source, provide a link to the Creative Commons license, and indicate if changes were made.

\section{References}

Adhikari TB, Cruz C, Zhang Q et al (1995) Genetic diversity of Xanthomonas oryzae pv. oryzae in Asia. Appl Environ Microbiol 61:966-971 
Bandillo N, Raghavan C, Muyco PA et al (2013) Multi-parent advanced generation inter-cross (MAGIC) populations in rice: progress and potential for genetics research and breeding. Rice 6:11. https://doi. org/10.1186/1939-8433-6-11

Brueggeman R, Druka A, Nirmala J et al (2008) The stem rust resistance gene Rpg5 encodes a protein with nucleotide-binding-site, leucine-rich, and protein kinase domains. Proc Natl Acad Sci 105:14970-14975. https://doi.org/10.1073/pnas.0807270105

Busungu C, Taura S, Sakagami J-I, Ichitani K (2016) Identification and linkage analysis of a new rice bacterial blight resistance gene from XM14, a mutant line from IR24. Breed Sci 66:636-645. https:// doi.org/10.1270/jsbbs. 16062

Cao A, Xing L, Wang X et al (2011) Serine/threonine kinase gene Stpk-V, a key member of powdery mildew resistance gene Pm21, confers powdery mildew resistance in wheat. Proc Natl Acad Sci 108:7727-7732. https://doi.org/10.1073/pnas.1016981108

Chen S, Liu X, Zeng L et al (2011) Genetic analysis and molecular mapping of a novel recessive gene $x a 34(t)$ for resistance against Xanthomonas oryzae pv. oryzae. Theor Appl Genet 122:13311338. https://doi.org/10.1007/s00122-011-1534-7

Chu Z, Fu B, Yang H et al (2006) Targeting xa13, a recessive gene for bacterial blight resistance in rice. Theor Appl Genet 112:455-461. https://doi.org/10.1007/s00122-005-0145-6

Dilla-Ermita CJ, Tandayu E, Juanillas VM et al (2017) Genome-wide association analysis tracks bacterial leaf blight resistance loci in rice diverse germplasm. Rice 10:8. https://doi.org/10.1186/s1228 4-017-0147-4

Dokku P, Das KM, Rao GJN (2013) Pyramiding of four resistance genes of bacterial blight in Tapaswini, an elite rice cultivar, through marker-assisted selection. Euphytica 192:87-96. https:// doi.org/10.1007/s10681-013-0878-2

Fu D, Uauy C, Distelfeld A et al (2009) A kinase-START gene confers temperature-dependent resistance to wheat stripe rust. Science (80) 323:1357-1360. https://doi.org/10.1126/science.1166289

Gu K, Tian D, Yang F et al (2004) High-resolution genetic mapping of $X a 27(t)$, a new bacterial blight resistance gene in rice, Oryza sativa L. Theor Appl Genet 108:800-807. https://doi.org/10.1007/ s00122-003-1491-X

Gu K, Yang B, Tian D et al (2005) R gene expression induced by a type-III effector triggers disease resistance in rice. Nature 435:1122-1125. https://doi.org/10.1038/nature03630

Iyer AS, Mccouch SR (2004) The rice bacterial blight resistance gene $x a 5$ encodes a novel form of disease resistance. Mol Plant Microbe Interact 17:1348-1354. https://doi.org/10.1094/ MPMI.2004.17.12.1348

Iyer-Pascuzzi AS, McCouch SR (2007) Recessive resistance genes and the Oryza sativa-Xanthomonas oryzae pv. oryzae pathosystem. Mol Plant Microbe Interact 20:731-739. https://doi.org/10.1094/ MPMI-20-7-0731

Ji H, Kim SR, Kim YH et al (2016) Map-based cloning and characterization of the BPH18 gene from wild rice conferring resistance to Brown Planthopper (BPH) insect pest. Sci Rep 6:1-13. https:// doi.org/10.1038/srep34376

Kauffman H, Reddy A, Hsieh S, Merca S (1973) An improved technique for evaluating resistance of rice varieties to Xanthomonas oryzae. Plant Dis Rep 57:537-541

Kim SM, Suh JP, Qin Y et al (2015) Identification and fine-mapping of a new resistance gene, Xa40, conferring resistance to bacterial blight races in rice (Oryza sativa L.). Theor Appl Genet 128:1933-1943. https://doi.org/10.1007/s00122-015-2557-2

Kim S-M, Reinke R, Kim B-K (2018) Correction to: developing japonica rice introgression lines with multiple resistance genes for Brown Planthopper, bacterial blight, rice blast, and rice stripe virus using molecular breeding. Mol Genet Genomics. https://doi. org/10.1007/s00438-018-1476-8
Kobayashi K, Sekine KT, Nishiguchi M (2014) Breakdown of plant virus resistance: can we predict and extend the durability of virus resistance? J Gen Plant Pathol 80:327-336. https://doi. org/10.1007/s10327-014-0527-1

Korinsak S, Sriprakhon S, Sirithanya P et al (2009) Identification of microsatellite markers (SSR) linked to a new bacterial blight resistance gene xa33 (t) in rice cultivar 'Ba7'. Maejo Intern J Sci Technol 3:235-247

Lee K-J, Kim K (2015) The rice serine/threonine protein kinase OsPBL1 (ORYZA SATIVA ARABIDOPSIS PBS1-LIKE 1) is potentially involved in resistance to rice stripe disease. Plant Growth Regul 77:67-75. https://doi.org/10.1007/s10725-015-0036-Z

Lee KS, Rasabandith S, Angeles ER, Khush GS (2003) Inheritance of resistance to bacterial blight in 21 cultivars of rice. Phytopathology 93:147-152. https://doi.org/10.1094/PHYTO.2003.93.2.147

Liang LQ, Wang CY, Zeng LX et al (2017) The rice cultivar Baixiangzhan harbours a recessive gene $x a 42(t)$ determining resistance against Xanthomonas oryzae pv. oryzae. Plant Breed 136:603609. https://doi.org/10.1111/pbr.12493

Liu GZ, Pi LY, Walker JC et al (2002) Biochemical characterization of the kinase domain of the rice disease resistance receptorlike kinase XA21. J Biol Chem 277:20264-20269. https://doi. org/10.1074/jbc.M110999200

Liu Q, Yuan M, Zhou Y et al (2011) A paralog of the MtN3/saliva family recessively confers race-specific resistance to Xanthomonas oryzae in rice. Plant, Cell Environ 34:1958-1969. https://doi.org /10.1111/j.1365-3040.2011.02391.x

Martin GB, Brommonschenkel SH, Chunwongse J et al (1993) Map-based cloning of a protein kinase gene conferring disease resistance in tomato. Science (80-) 26:1432-1436. https://doi. org/10.1126/science.7902614

McCouch SR, Zhao K, Wright M et al (2010) Development of genomewide SNP assays for rice. Breed Sci 60:524-535. https://doi. org/10.1270/jsbbs.60.524

McDowell JM, Woffenden BJ (2003) Plant disease resistance genes: recent insights and potential applications. Trends Biotechnol 21:178-183. https://doi.org/10.1016/S0167-7799(03)00053-2

Meng L, Li H, Zhang L, Wang J (2015) QTL IciMapping: integrated software for genetic linkage map construction and quantitative trait locus mapping in biparental populations. Crop J 3:269-283. https://doi.org/10.1016/j.cj.2015.01.001

Mew TW (1987) Current status and future prospects of research on bacterial blight of rice. Annu Rev Phytopathol 25:359-382. https ://doi.org/10.1146/annurev.py.25.090187.002043

Mew TW (1993) Focus on bacterial blight of rice. Plant Dis 77:5-12. https://doi.org/10.1094/PD-77-0005

Murray MG, Thompson WF (1980) Rapid isolation of high molecular weight plant DNA. Nucleic Acids Res 8:4321-4326. https://doi. org/10.1093/nar/8.19.4321

Nelson RJ, Baraoidan MR, Vera Cruz CM et al (1994) Relationship between phylogeny and pathotype for the bacterial blight pathogen of rice. Appl Environ Microbiol 60:3275-3283

Pradhan SK, Nayak DK, Mohanty S et al (2015) Pyramiding of three bacterial blight resistance genes for broad-spectrum resistance in deepwater rice variety. Jalmagna. Rice 8:51. https://doi. org/10.1186/s12284-015-0051-8

RDA (Rural Development Administration) (2012) Manual for standard evaluation method in agricultural experiment and research. RDA Press, Suwon (Korea)

Reddy APK, MacKenzie DR, Rouse DI, Rao AV (1979) Relationship of bacterial leaf blight severity to grain yield of rice. Phytopathology 69:970. https://doi.org/10.1094/Phyto-69-970

Sharma P, Bora LC, Puzari KC et al (2017) Review on bacterial blight of rice caused by Xanthomonas oryzae pv. oryzae: different management approaches and role of Pseudomonas fluorescens as a 
potential biocontrol agent. Int J Curr MicroibolApp Sci 6:9821005. https://doi.org/10.20546/ijcmas.2017.603.117

Shen Y-J, Jiang H, Jin J-P et al (2004) Development of genome-wide DNA polymorphism database for map-based cloning of rice genes. Plant Physiol 135:1198-1205. https://doi.org/10.1104/ pp. 103.038463

Singh S, Sidhu JS, Huang N et al (2001) Pyramiding three bacterial blight resistance genes (xa5, xa13 and Xa21) using markerassisted selection into indica rice cultivar PR106. Theor Appl Genet 102:1011-1015. https://doi.org/10.1007/s001220000495

Song W-Y, Wang G-L, Chen L-L et al (1995) A receptor kinaselike protein encoded by the rice disease resistance gene, $\mathrm{Xa21}$. Science (80-) 270:1804-1806. https://doi.org/10.1126/scien ce.270.5243.1804

Srinivasan B, Gnanamanickam SS (2005) Identification of a new source of resistance in wild rice, Oryza rufipogon to bacterial blight of rice caused by Indian strains of Xanthomonas oryzae pv. oryzae. Curr Sci 88:1229-1231

Suh J-P, Noh T-H, Kim K-Y et al (2009) Expression levels of three bacterial blight resistance genes against K3a race of Korea by molecular and phenotype analysis in japonica rice (O. sativa $\mathrm{L}$.). J Crop Sci Biotechnol 12:103-108. https://doi.org/10.1007/s1289 2-009-0103-y

Suh J-P, Jeung J-U, Noh T-H et al (2013) Development of breeding lines with three pyramided resistance genes that confer broadspectrum bacterial blight resistance and their molecular analysis in rice. Rice 6:5. https://doi.org/10.1186/1939-8433-6-5

Sun X, Cao Y, Yang Z et al (2004) Xa26, a gene conferring resistance to Xanthomonas oryzae pv. oryzae in rice, encodes an LRR receptor kinase-like protein. Plant J 37:517-527. https://doi. org/10.1046/j.1365-313X.2003.01976.x

Sundaram RM, Vishnupriya MR, Biradar SK et al (2008) Marker assisted introgression of bacterial blight resistance in Samba
Mahsuri, an elite indica rice variety. Euphytica 160:411-422. https://doi.org/10.1007/s10681-007-9564-6

Thomson MJ, Zhao K, Wright M et al (2012) High-throughput single nucleotide polymorphism genotyping for breeding applications in rice using the BeadXpress platform. Mol Breed 29:875-886. https ://doi.org/10.1007/s11032-011-9663-X

Tian D, Wang J, Zeng X et al (2014) The rice TAL effector-dependent resistance protein XA10 triggers cell death and calcium depletion in the endoplasmic reticulum. Plant Cell 26:497-515. https://doi. org/10.1105/tpc. 113.119255

Tung CW, Zhao K, Wright MH et al (2010) Development of a research platform for dissecting phenotype-genotype associations in rice (Oryza spp.). Rice 3:205-217. https://doi.org/10.1007/s 1228 4-010-9056-5

Vera Cruz CM, Bai J, Oña I et al (2000) Predicting durability of a disease resistance gene based on an assessment of the fitness loss and epidemiological consequences of avirulence gene mutation. Proc Natl Acad Sci USA 97:13500-13505. https://doi.org/10.1073/ pnas. 250271997

Vikal Y, Bhatia D (2017) Genetics and Genomics of Bacterial Blight Resistance in Rice. In: Li DBE-J (ed) IntechOpen, Rijeka, chap 10

Vincze T, Posfai J, Roberts RJ (2003) NEBcutter: a program to cleave DNA with restriction enzymes. Nucleic Acids Res 31:3688-3691. https://doi.org/10.1093/nar/gkg526

Wang C, Zhang X, Fan Y et al (2015) XA23 is an executor R protein and confers broad-spectrum disease resistance in rice. Mol Plant 8:290-302. https://doi.org/10.1016/j.molp.2014.10.010

Yokotani N, Sato Y, Tanabe S et al (2013) WRKY76 is a rice transcriptional repressor playing opposite roles in blast disease resistance and cold stress tolerance. J Exp Bot 64:5085-5097. https://doi. org/10.1093/jxb/ert298 